\title{
The establishment of a Brazilian Nacional Data Center (NDC) for a better Comprehensive Nuclear Test-Ban-Treaty verification regime
}

Lucas Vieira Barros ${ }^{1}$, Brandow Lee Neri ${ }^{1}$, Juraci Mario de Carvalho ${ }^{1}$ and Darlan Portela Fontenele ${ }^{1}$

${ }^{1}$ Seismological Observatory, University of Brasilia, Brazil

Copyright 2021, SBGf - Sociedade Brasileira de Geofísica

This paper was prepared for presentation during the $17^{\text {th }}$ International Congress of the Brazilian Geophysical Society held in Rio de Janeiro, Brazil, 16-19 August 2021

Contents of this paper were reviewed by the Technical Committee of the $17^{\text {th }}$ International Congress of the Brazilian Geophysical Society and do not necessarily represent any position of the SBGf, its officers or members. Electronic reproduction or storage of any part of this paper for commercial purposes without the written consent of the Brazilian Geophysical Society is prohibited.

\section{Abstract}

The Comprehensive Nuclear Test-Ban-Treaty (CTBT) prohibits conducting nuclear tests on a global scale. Although not yet in force, it has an International Monitoring System (IMS) based on geophysical sensors, capable of globally detect any nuclear test equal or greater than $1 \mathrm{kt}$ (kiloton) of TNT. The Sensors of the global IMS network use four technologies: Seismic; Infrasound; Hydroacoustics and Radionuclides. Data from the IMS network are transmitted to the International Data Center (IDC), located at the United Nations in Vienna - Austria. The IDC has the mission of processing, analyzing and issue bulletins/reports on any event of interest to treaty compliance. But, only the State Parties, through their NDCs and National Authorities (NA), can declare an event to be suspicious and possible linked to a clandestine nuclear explosion. The Brazil, despite of having already signed and ratified the Comprehensive Nuclear Tests-BanTreaty (CTBT), does not have yet an established NDC, which is a center with expertise in verification technologies operating under the guidance of the National Authority. The NA is the main Point of Contact of a State Party to the CTBT, International Data Center and other States Parties. Therefore, a NDC plays a key role in overseeing compliance with the CTBT. Brazil contributes with data from three technologies: Seismic, Infrasound and Radionuclides. The Seismological Observatory (SIS) of the University of Brasília (UnB) contributes with data from two stations, a primary seismic station and an infrasound station, both located inside the Brasília National Park (PNB). Data from these stations are transmitted to the (SIS - UnB), where they are recorded, analyzed and retransmitted to the IDC. The other IMS stations in Brazil are: two auxiliary seismic stations, located in the states of Rio Grande do Norte and Amazonas; two radionuclide stations, located in Rio de Janeiro and Recife (planned), and a radionuclide laboratory, located at the Institute of Radioprotection and Dosimetry (IRD), also at the city of Rio de Janeiro. In this text, we present a description of a NDC, with definition, attributions and requirements for its assembly and operation.

\section{Introduction}

Brazil's National Data Center (NDC) has not yet been formally established, although, according to the CTBT, NDCs can be created in any State Party. A NDC is an organization with expertise in verification technologies that functions as part of (or under the guidance of) a National Authority.

The CTBT Treaty consists of 1 preamble, 17 articles, 2 annexes and 1 protocol with 2 annexes. The text of the Resolution adopted by the CTBT Signatory Countries or States Parties also integrates the Treaty, establishing the Preparatory Commission for the Comprehensive NuclearTest-Ban Treaty Organization - PrepCom/CTBTO, with the objective of carrying out the necessary preparations for the effective implementation of the CTBT and guaranteeing the operationalization of the Treaty's verification regime, upon its entry into force, which is subject to ratification by the 44 countries listed in Annex 2 of the CTBT.

Brazil signed the Treaty on $9 / 26 / 1996$, ratified it on $7 / 24 / 1998$ and participates in its verification under three technologies: seismic, infrasound and radionuclides. A treaty, when in force, is an agreement between States with the obligations of each State Party governed by international law. The Vienna Convention on the Law of Treaties provides that all States Parties to a treaty must contribute to the achievement of its objectives and purposes. These are obligations of Brazil to the CTBT (as well as those of other States Parties), in addition to the commitment not to carry out any type of nuclear explosion, to prohibit and prevent any nuclear test anywhere under its jurisdiction or control, to contribute to the Treaty verification with data from your stations and participate in the investigation and identification of suspicious events.

The identification of suspected clandestine test events will occur through the analysis and interpretation of signals detected by geophysical sensors of four specific technologies, capable of detecting any nuclear test with a power greater than or equivalent to 1 kiloton (kt) of TNT (trinitrotoluene). After detecting, locating, and identifying a suspicious event, an on-site inspection is carried out to confirm whether a nuclear test has taken place.

In June 2019, on the fourth Science and Technology Conference (SnT4/2019) promoted by the CTBTO, in Vienna - Austria, the Brazilians participating in this event were invited by the ambassador of the Brazilian Permanent Mission to the UN in Vienna, minister Marcel Fortuna Biato, for a meeting, when we had the opportunity to discuss the creation of a NDC in Brazil. After this event, the authors of this article wrote the book: The Brazilian Participation in the Verification of the Comprehensive Nuclear Teste-BanTreaty

(http://obsis.unb.br/portalsis/?pg=viewNotice\&id_notice $=3$ 8). This book is based mainly in the authors experiences in more than 20 years working with seismic and infrasound technologies. The book presents the most relevant parts of the CTBT, emphasizing the obligations of a State Party in its verification, with emphasis on the Brazilian participation 
in the Treaty's verification regime. The four technologies of the global sensor network are also presented and described, as well as the synergy between them.

In this article we deal with the creation of the Brazilian NDC addressing the following important points of a NDC: its role in the verification system; the Treaty articles relating to a NDC and the National Authority; the structure of a NDC and the appropriate organizations to host it; establishing a secure account for the reliable transmission of IDC data and products; IDC's data and product user registration procedures; the operation and possible functions of a NDC; and the scientific and social applications of IMS data and IDC products.

There are several benefits of Member Countries with a NDC, such as: unrestricted access to raw and/or processed data; access to training and capacity building; access to software and technical support; access to a protected website that provides a platform for discussions and exchange of confidential information, etc. The use of IMS data and IDC products is not restricted to the applications mentioned in this text. By accessing data from this global network, Brazilian scientists will be able to develop studies and research in all areas of knowledge related to natural and anthropogenic phenomena that can be observed and measured by this global network of sensors.

\section{Role of a National Data Center}

Under the Treaty, IMS data is analyzed at the IDC in Vienna and at National Data Centers (NDCs), which can be set up in all States Parties, with a country having more than one NDC, located in establishments separate and dealing with one or more of the IMS technologies. A State Party, in addition to committing not to carry out nuclear tests, is also a participant in their verification. A NDC is therefore operated and maintained by a State Party. Its functions may include sending data from IMS stations to IDC as well as receiving data and products from IDC. The NDC must routinely analyze the data acquired by the stations located in the respective State Party, and generate bulletins, reporting them to the IDC. For that, computational tools developed by CTBTO are used, all integrated to the software package called NDC-in-a-Box.

\section{Treaty Articles related to the NDC and the national authority}

Article III, Paragraph 4, provides that, to fulfill its obligations under the Treaty, each State Party shall designate or establish a National Authority and inform the Organization (CTBTO) as soon as the Treaty enters into force. The National Authority will serve as the national focal point with the Organization and other Member States. Article IV, Paragraph 18, says that each State Party shall cooperate with the International Data Center through its National Authority. Article IV, Paragraph A3, establishes that each State Party undertakes [...] to cooperate, through its National Authority [...] with the Organization and with other States Parties:

(A) Establishing the facilities and means of communication necessary to participate in Treaty verification.
(B) Providing data obtained from national stations that are part of IMS.

(C) Participating, as appropriate, in consultation and clarification processes.

(D) Participating, as appropriate, in strengthening measures of trust.

Raw or processed data from the IMS is transmitted to the IDC from a NDC or directly from monitoring stations, laboratories, or analysis facilities at different intervals (Figure 1):
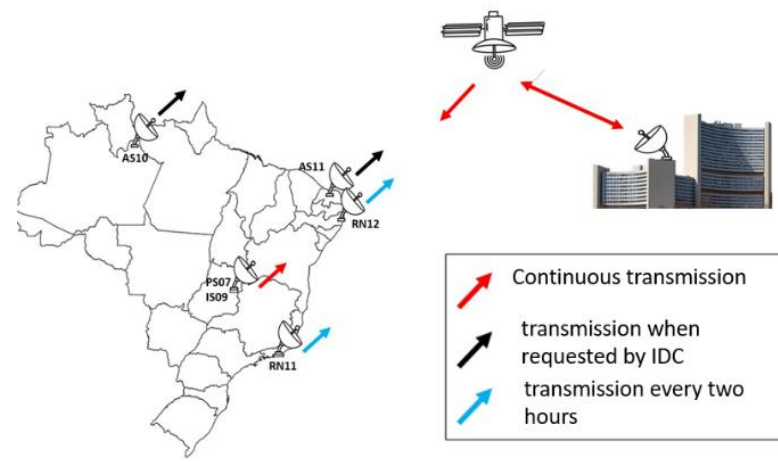

Figure 1: Brazilian IMS stations and data transmission method for IDC in Vienna - Austria.

- Uninterruptedly - primary seismic, infrasound and hydroacoustic stations;

- Every two hours - radionuclide stations;

- The International Data Center shall, where necessary, provide technical assistance to each State Party, helping to develop the capacity to receive, process and analyze IMS data;

-When requested - auxiliary seismic stations.

\section{The role of the NDC in the CTBT verification system}

The role of NDCs is outlined in (Figure 2) and consists of:

- Advise the National Authority:

- Checking the nature of events, in accordance with the Treaty;

- Reviewing proposed technical changes for system verification;

- Providing technical advice to representatives on the Executive Board.

- Use data from IMS and IDC products, as needed, to assist with verification efforts;

- Provide scientific knowledge to subsidiary technical bodies (Scientific Council, scientific expert working groups);

- Acting as an interface for national scientific organizations and for civil applications of verification technologies.

- Be responsible for the proper use of IMS data and IDC products. 


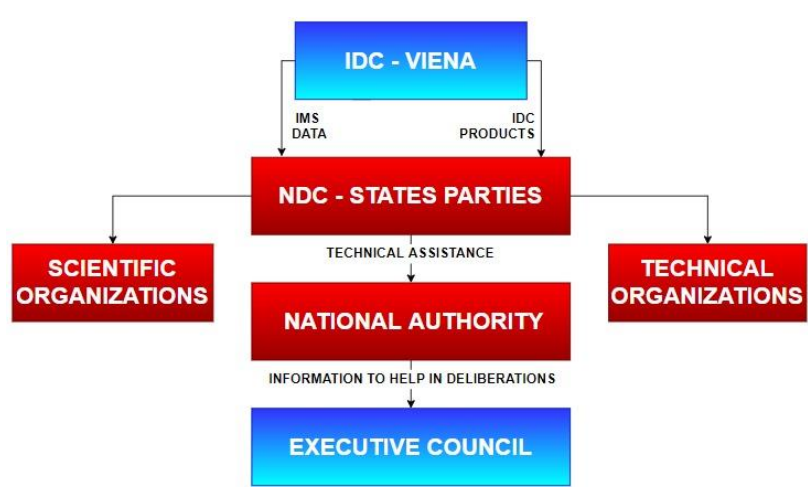

Figure 2: Data and information flow diagram between IDC and States Parties.

\section{Structure of a NDC and Appropriate Organizations to Host It}

The establishment and operation of a NDC is done by national regulation. It may be based at an institution(s) specializing in the verification and monitoring of technologies related to the Treaty. Various types of organizations can host it, such as: Ministry of Foreign Affairs (Belize and Thailand); Departments of Geophysics/Geology (Australia); Geophysics Institute and Observatory (Madagascar); Geological Survey (Canada, Colombia, Denmark); Nuclear Regulatory Authority (Argentina); Nuclear Research Institute (Philippines); Radiation and Nuclear Safety Authority (Finland); National Nuclear Safety and Safeguards Commission (Mexico); Universities (Albania, Costa Rica, Czech Republic, Turkey, Brazil), Atomic Energy Agency (Japan, Malaysia, Poland, Sweden, etc.), Seismological Service (Brazil, Jordan, Georgia, Malta).

\section{IDC Product and Data Users}

To gain access to IDC's data and products, a Secure User Account, authorized by the respective State Party, is required to allow access to IDC's secure portal. To register a secure account, you must complete the registration form provided by PTS and be designated as a user by the Main Point of Contact. IDC data and products can be accessed:

1. By the Provisional National Authority and NDCs of Signatory States. NDCs can be subdivided, with each subdivision located in a separate facility and dealing with one or more of the IMS technologies;

2. By Scientific Disaster Alert Organizations, through agreements made and discussed within the scope of Work Group B (WGB). Data is not publicly available, except for the following institutions:

1. International Seismological Center (ISC), Newbury United Kingdom, limited to REB bulletin;

2. World Meteorology Organization (WMO), Vienna Austria, limited to meteorological observation data from Radionuclide stations;

3. International Scientific Studies Project (ISS), whose objective is to carry out, in a coordinated international effort, independent scientific studies and evaluations to approach the agility and capacity of the CTBT verification system. The resulting new scientific material will assist States Parties in assessing the verifiability of the Treaty.
4. Tsunami Centers - The 27th Session of the CTBTO Provisional Technical Secretariat (PTS) held from November $13^{\text {th }}$ to $17^{\text {th }}, 2006$, decided that primary seismic, auxiliary seismic and hydroacoustic data can be provided to organizations of tsunami alert approved by the United Nations Educational, Scientific and Cultural Organization (UNESCO - United Nations Educational Scientific and Cultural).

The distributed data includes more than 100 IMS Network seismic and hydroacoustic technology stations, located primarily in high tsunami risk areas. Currently, the following countries have access to IMS data: Madagascar, Australia, France, Greece, Indonesia, Japan, Republic of Korea, Malaysia, Myanmar, Philippines, Portugal, Thailand, Turkey, Russia, and the United States.

\section{Steps to Becoming IMS Data User and IDC Producers}

1. Become an Authorized User and report to IDC. Only authorized users may access IDC's products and services. A completed Registration Form allows PTS to activate a single secure signatory account for each State Party. The first completed Registration Form is sent through official channels (your Permanent Mission).

2. Receive information from IDC. Authorized users receive information from IDC about user accounts and passwords.

3. Connect to IDC. Communication links between the NDCs and the IDC are provided by the VPN connection (via the Internet) and/or the $\mathrm{GCl}$ (managed by the IDC).

\section{Establishing a Secure IDC Account and User Class}

A Member State wishing to use its right of access the monitoring data and analysis reports must establish a Secure Signatory Account on the Security Web Portal at the CTBTO. This is the mechanism by which authorized users can communicate with IDC and securely transfer data. The Signatory State will designate a person, called the Primary Point of Contact, who will be the overall responsible for the State Signatory Secure Account for the purposes of initial testing with IDC. Any changes in the status of the account or users must be communicated to PTS through the Main Point of Contact.

Three classes of users, appointed by the Primary Point of Contact and authorized by the Signatory State, may access IMS data and IDC products through the Single Secure Signatory Account established by each State Party:

Main users (limit: 18 users from up to 6 establishments), with access to all IMS data and IDC products via IDC's secure website or email (AutoDRM). These users can request data subscriptions, establish event data filters, and request expert technical assistance.

Regular users (limit: normally up to 10) - Restricted access to IDC's secure website.

Station Operators and Station Maintenance Technicians (no defined limit) - Restricted access to station status information and your station's waveform data that are already stored in the IDC. 


\section{Possible ways to receive IDC data:}

- Continuous data from primary seismic, hydroacoustic and infrasound stations;

- By requests via AutoDRM.

Daily data access is limited to: $150 \mathrm{MB} /$ day via GCl; 500 $\mathrm{MB} /$ day via VPN link, via the Internet. The limitation is not the amount of data distributed, but the communication costs.

\section{AutoDRM requests are limited to $600 \mathrm{MB} /$ day per user.}

\section{Discussion and conclusion}

In this text, we discuss the Brazilian participation in the verification regime of the Comprehensive Nuclear TestBan-Treaty (CTBT); the obligations of Brazil as a State Signatory of the CTBT and the actions necessary for the implementation of the Treaty, as well as the establishment of the means and conditions by which the Treaty can enter into force, be complied with and verified. The four technologies employed by the global sensor network were described and presented in the context of Brazilian participation in the CTBT.

The use of IMS data and IDC products for scientific and social purposes was highlighted as an advantage to be achieved from the establishment of the Brazilian NDC, as a NDC facilitates technical interaction between a Member State and the CTBTO.

As this is a national issue, the CTBTO cannot require a Member State to have a NDC, however, it strongly encourages its establishment, capacity building and contribution.

Currently, about 130 Member States have NDCs. A NDC helps a Member State fulfil its role under the Treaty by assisting in analyzing data and interpreting reports provided by IDC or other State Parties. Optionally member states with IMS stations, as the case of Brazil, the NDC can play a key role in operating the stations and transmitting data to IDC in Vienna. Upon the Treaty entry into force, a NDC may assume additional responsibilities in relation to other verification measures, such as: providing information on chemical explosions (location of mineral exploration areas) to IDC, on a voluntary basis (confidence-building measures); make available information obtained from cooperating national facilities, such as, for example, data from stations of the Brazilian Seismographic Network; provide information about reference events, contributing to the establishment of more accurate propagation models; participate in calibration projects by providing additional region- or site-specific knowledge.

The CTBTO provides technical assistance that allows Member States to work with IDC monitoring data and outputs. This assistance includes distributing and helping to install a software package: NDC-in-a-Box, used to process IMS data. In addition, the CTBTO contributes to the establishment of the communication links for accessing IDC data, products and assists in training the personnel necessary for a Member State to assume its responsibilities and enjoy its rights under the Treaty.
- The establishment of a NDC in Brazil shows that the country is willing to participate more effectively in the verification of the CTBT;

- The NDC can function as a center for knowledge irradiation in Brazil on civil and scientific applications of CTBT verification technologies;

- The NDC can serve as an interface between IDC, scientific organizations in the States Parties and the various research centers linked, mainly, to Brazilian universities for the dissemination of knowledge. These actions will take place through the promotion of training courses, workshops and technical-scientific meetings, with the participation of guest researchers from other institutions abroad that deal with IMS technologies and civil and scientific applications of the Global Data Network;

- The NDC can promote discussions and provide technicalscientific assistance in the implementation of research centers and centers aimed at the processing and analysis of waveform signals from the three technologies of the IMS, and also bring together Brazilian researchers in the area of radionuclides;

- The NDC might enable the creation of research centers in the area of seismology, infrasound, hydroacoustics and radionuclides at the Brazilian universities, through the use of data from the IMS in synergy with the Brazilian Seismographic Network (RSBR);

- The NDC can provide national events aimed at the interaction between the various national research centers and centers on scientific applications of CTBTO technologies.

The recent explosion in Beirut. Studied in the book The Brazilian Participation in the Verification of the Comprehensive Nuclear Teste-Ban-Treaty, wireted by the article authors, proved to be particularly important to show the capacity of the Brazilian experts to detect and identify such an event alike a nuclear explosion in the atmosphere. This type of event is important to calibrate the international monitoring system and test the atmospheric models. Finally, a NDC's main role is to support the State Party in detecting, locating, and classifying events of interest in verifying the CTBT Treaty.

\section{Acknowledgements}

The authors are grateful to the Preparatory Commission of the Comprehensive Nuclear Test Ban Treaty Organization (PrepCom - CTBTO) for the opportunity of the numerous trainings received and for the availability of data and information that supported the preparation of this text. To the Disarmament and Sensitive Technologies Division DDS, from the Ministry of Foreign Affairs, for supporting the Seismological Observatory of the University of Brasília in the establishment of cooperation with the PrepCom CTBTO. To the Central Administration of the University of Brasília for their willingness to rapidly forward the processes related to the establishment of cooperation with the United Nations, in the implementation of seismic and infrasonic stations within the Brasília National Park, to whom we also thank.

Conclusively, we can state that: 


\section{References}

Barros, L.V., Neri, B. L., Carvalho, J. M. and Fontenele, B. P. 2020. A Particpação Brasileira na Verificação do Tratado de Proibição Total de Teste Nucleares. Editora Copiart, $152 \mathrm{p}$. 